\title{
Litigation and complaints procedures: objectives, effectiveness and alternatives
}

\author{
Christopher J Whelan University of Warwick School of Law
}

\section{Author's abstract}

Recent debates about redress mechanisms for medical accident victims have been sidetracked by fears of an American-style medical malpractice crisis. What is required is a framework within which the debate can resume. This paper proposes such a framework by focusing on the compensation and deterrence objectives and placing them in the wider context of the social costs of providing medical services.

The framework is then used to assess and compare the effectiveness of differing approaches. In particular, the American and British experiences of litigation, including the concept of 'defensive medicine', are evaluated. Also discussed briefly are alternatives to court-based complaints procedures including 'no-fault' schemes, professional ethics and internal complaints mechanisms.

\section{Introduction}

Current debates about methods of complaint for the users of health care services are in danger of being overshadowed or even swallowed up by arguments about an American-style 'malpractice crisis', the rights of patients to medical information and of victims to compensation. The competing claims that there is already (or very soon to be) a malpractice crisis and that victims of malpractice go without redress are of course somewhat difficult to reconcile. This is not to say that there are not horror stories on both sides of the argument (and indeed of the Atlantic). However, there is a danger that dialogue will become increasingly polarised in character. The purpose of this paper is to return briefly to the 'general principles' of complaints procedures. In particular, I wish to propose a framework within which the effectiveness of various complaints procedures can be assessed. To do this it is necessary to look critically at the goals of complaints procedures. These goals are usually taken for granted, but in making them explicit here, the advantages and disadvantages of alternative procedures may become more apparent. Moreover, by focusing on what we know or need to find out, rather than on what we think

\section{Key words}

Malpractice claims; medical litigation; compensation. we know and on anecdote, further debate on the basis of this framework may more meaningfully take place.

\section{Objectives}

Complaints procedures may serve a wide variety of objectives, some of which no doubt will be in conflict. I would suggest, however, that the two major objectives can be characterised as compensation and deterrence. This is not to suggest that other objectives may not also be very important. No doubt many health care users wish very often to complain in order to establish a principle - they have a genuine grievance, they wish that it be acknowledged and want no more than that, except perhaps to receive an apology or an explanation. Others may simply wish to extract information from the medical side. These and other objectives might lead one to advocate one or other form of control: internal complaints procedures (selfregulation), government regulation, or victim-initiated external controls. However, in the interests of brevity, I intend to focus on the compensation and deterrence goals of complaints procedures. I wish to suggest that these goals may be used as the primary measure or yardstick with which to assess the effectiveness of alternative procedures. They are not, however, the simple concepts that they are sometimes taken to be.

\section{COMPENSATION}

The general proposition underlying the goal of compensation is that it is just and equitable that the victims of a failure to exercise an acceptable and proper degree of care (that is the victims of negligence), who suffer losses through no fault of their own, should be compensated for those losses. This is unexceptionable in principle, but, in the real world, it is more complicated than it sounds, for it encompasses a number of difficult questions: how should the risks of losses be shared between the medical side and the victims and how should they be shifted to third parties, including insurance companies, other members of the profession or the community?

\section{DETERRENCE}

The general proposition underlying the goal of deterrence is that the quality of medical services will be 
improved if complaints procedures penalise those who do not exercise an acceptable degree of care. In other words, complaints procedures are effective if they provide incentives to take a proper degree of care.

Deterrence can be understood in a number of ways. The idea that those who would otherwise not exercise an acceptable degree of care will be deterred from such behaviour can also be presented in terms of prevention of negligence. In order to prevent accidents, a standard of care will be established (for example, by the courts); failure to maintain that standard will be penalised. The idea of prevention can itself be presented in terms of quality control; complaints procedures can be used to monitor the quality of service, ensure that adequate standards are maintained and deal with failures or gaps in the system.

The general proposition that deterrence, prevention and quality control will help to improve the quality of medical services is also unexceptionable; few, if any, would disagree with it in principle. But, this general goal is also much more complicated in practice, because one cannot look at it (nor indeed the compensation goal) in isolation from the question of the social costs of providing medical services.

\section{SOCIAL COSTS}

There are three primary components (or burdens) to the social costs of quality. First, there is the burden of taking greater care. If complaints procedures do indeed penalise lower levels of care and create incentives to take a higher degree of care it is inevitable that they will also have imposed costs: greater care is for the most part costly. Secondly, there is the burden of losses. Lack of care also is costly in that losses are inflicted on the 'victims'. Finally, there is the burden of complaints procedures themselves. Administering complaints procedures (and regulating quality) is costly: expenses, fees, time and, in the medical context, the adoption of 'defensive' practices are costly. If complaints procedures create the wrong incentives and impose the wrong standard of care, this too will be costly. Thus, the general principle of deterrence must also take into account the 'economics' of health care provision, and complaints procedures should have as one of their goals the reduction in the social costs of providing medical services. The deterrence goal should be viewed, therefore, not just as an attempt to achieve the highest quality but should take into account also the various costs involved in the provision of medical care.

This is very important when it comes to evaluating the effectiveness of complaints procedures. The legal system, for example, which provides victims of negligence with a remedy under the law of tort, has been criticised as being an excessively costly and cumbersome method of deterring losses (and indeed of compensating victims). However, this alone is never a sufficient criticism. The effectiveness of the law and legal rules, and indeed of other complaints procedures, should be determined by weighing the legal costs of liability rules against the reduction in quality costs they encourage. In other words, if a complaints procedure helps to avoid widespread losses to victims by creating incentives to take care, and if the cost of providing extra care is not excessive, then that complaints procedure will achieve its goal, provided that the procedure is not itself too costly to administer. It is of paramount importance therefore that the various costs of alternative complaints procedures and their interrelationships be known in order that evaluation and comparison can be effective. Until we have current $\vec{\circ}$ information on these matters, a proper assessment cannot be undertaken. I will return to this theme later.

In the remainder of this paper some of the advantages and disadvantages of various complaints procedures will be discussed, utilising the twin goals of $\vec{f}$ deterrence and compensation as the yardstick for + v evaluation. Given the current climate of concern over a $\partial$ possible 'medical malpractice' crisis, most attention 온 will be paid to the mechanism of civil liability for negligence.

\section{Litigation}

There is little doubt that the prospect of an Americanstyle medical malpractice litigation explosion is a spectre haunting many corners of the British medical profession. Although civil liability is not a new phenomenon in this country - the first recorded medical malpractice case was in 1374 (1) - fears that there is now an increased willingness to sue and that there has been a general rise in the level of awards has led to a widespread expression of concern. These fears have been aggravated (if not created) by the recent increases in medical defence society subscriptions.

There is no doubt that malpractice claims in the United States have grown in size and frequency since 1970. Between 1970 and 1986 the number of claims per insured physician increased more than four times, and it appears as though the average costs of damage awards paid by defendants to plaintiffs have increased faster than inflation (2). The 'crisis' in the United $\frac{\text { T }}{2}$ States has also been aggravated (if not created) by the rapid increase in the cost of insurance and the $N$ subsequent difficulties encountered by doctors in $N$ obtaining insurance.

It is however extremely difficult to estimate the $\omega$ gravity of the problem in the United States. It is widely believed that the malpractice situation has led to the $\stackrel{0}{\mathrm{C}}$ practice of 'defensive medicine' and a shift in the distribution and activities of doctors. Regarding ? defensive medicine, the use of additional testing and procedures may have had more to do with the lack of $\frac{\mathbb{D}}{\mathbb{D}}$

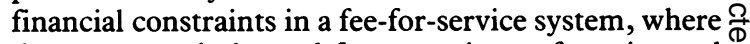
doctors are reimbursed for every item of service and $\varrho$ thereby exercise a high degree of control over their incomes, than with fears of litigation. Indeed, where 8 the prospective payment system has been used, in which a flat rate for patients is paid out of which all services must be provided, the volume of tests and 
procedures seems to be declining, despite the concern over litigation (3). Regarding the distribution and activities of doctors also, it is difficult to isolate the effects of malpractice claims and insurance premiums from factors such as the payments system, long-term health care planning objectives, such as the growth in specialisation, and other changes in society and the economy more generally (2). However, the percentage of gross income spent by doctors on insurance has remained roughly stable for a decade now at less than 4 per cent of income (4).

In this country, there is no reliable data on the extent of the 'crisis' and the gravity of the problem. As with the United States, however, it is probably true here that claims have grown in size and frequency in recent years. What is certainly true, and what has fuelled concern within the British medical profession, is that there has been a sharp increase in medical defence subscriptions; the most recent being the 70 per cent increase in the Medical Defence Union and Medical Protection Society subscriptions in 1987. There are similar fears that the growing number and size of negligence claims means that doctors here are also practising defensive medicine and that recruitment to certain specialities may be affected. In addition, there is concern that such claims may act as a drain on National Health Service (NHS) resources.

It is not possible to explore the extent of the 'crisis' here; what is more important is to note that such a crisis is perceived and that American experience is commonly cited as a warning of what may happen here. It may come as a surprise to some doctors to realise that the crisis has reached other professions in Britain more quickly than their own. Indeed, their malpractice adversary, the solicitor, has not only for many years had to pay much higher insurance premiums than his medical counterpart, but the solicitor's profession, more generally, is now unable to find adequate commercial insurance (5). Accordingly, as happened in the United States medical profession, the Law Society has proposed to establish a solicitor-owned mutual insurance scheme to provide half of the required insurance cover.

With the widespread expression of concern over litigation, it may be apposite to reflect on the potential role of civil liability as a means of achieving the objectives not only of compensation but also of deterrence. For this is what the law actually proposes: by making those responsible for causing losses through their negligence liable to compensate their victims, the law purports to further both objectives.

It is sometimes claimed that damages for negligence do not penalise the defendant and that they only compensate the plaintiff. That, however, is a contentious claim for several reasons. In the first place, it must be remembered that the system of civil liability is only available to victims who can prove negligence on the part of the defendant. In the tort system the degree of injury and loss is irrelevant to the question of liability; that system does not focus upon the needs a victim may have, but upon the cause of the injury, that is, upon the question: who was at fault (6)? Secondly, if the tort system was designed only to compensate, then it could and should be abolished immediately, for most victims, including victims of negligence are unor under-compensated in that system (7). There are much more effective and cheaper methods of compensating accident victims, including the 'nofault' systems which will be discussed below.

The system of civil liability penalises lack of proper care by making the negligent party bear the costs of the accident. Thus, a plaintiff who succeeds in proving negligence against a defendant receives damages (compensation) from that defendant. It is the defendant who has to pay. Conversely, if an accident victim, no matter how injured, cannot find anyone responsible for causing the accident, or if the victim himself was to blame (wholly or partly), he cannot obtain (full) compensation through the tort system.

It might be argued that the insurance system insulates defendants from the concerns of the tort system. If defendants do not pay damages personally, and if insurance premiums are not related to claims experience, then such a proposition is correct (at least as regards cost pressures). However, if there are no cost incentives on a professional to take care, then it is the insurance system, not the tort system, which is faulty in relation to the deterrence objective.

The final point one can make in refuting the claim that damages for negligence do not penalise defendants is perhaps the most powerful to those who prefer to theorise from the armchair rather than do the research that is required. If damages do not penalise defendants (doctors) then why should doctors engage in defensive practices to avoid the charge that they have been negligent? In other words, the whole debate about defensive medicine as a response to fears of litigation (to be discussed further below) assumes that doctors will have to pay - whether personally or through higher insurance premiums. It is to avoid that penalty that defensive practices may be devised. If there is no penalty, such a response would be totally irrational.

Civil liability for negligence has a number of potential advantages. First, damages for negligence directly penalise those who have been negligent, and thus act as a 'tax' on carelessness which will induce doctors and others to take more care to avoid future liability. Secondly, by imposing liability on the more knowledgeable party, civil liability encourages loss avoidance and improves the flow of information. The medical side is better able not only to bear the loss (possibly through insurance) but also to avoid the loss (through knowledge of how to do it). Moreover, information about the quality of medical services can be provided more easily by imposing liability on negligent professionals; users of the health service as well as fellow professionals will be better able to know who is and who is not providing proper service. Thirdly, civil liability is perhaps a less restrictive form of legal intervention in medical practices than, say, 
government regulation of quality standards or selfregulation by the profession itself. Finally, civil liability may currently have a practical virtue. It is probably the only means by which 'ordinary' as opposed to 'gross' negligence can be controlled. Serious professional misconduct which would invoke disciplinary proceedings is limited to gross professional negligence.

These are some of the potential advantages, apparent or real, to which civil liability for professional negligence may lay claim. What are the disadvantages, apparent or real? First, there is the general proposition that it is of great importance that the medical profession perform their functions free from what may be called litigation harassment. This proposition is so often cited that it justifies further examination. Litigation harassment has two major components of fear: first, there is the floodgates of litigation fear, that a rash of suits will be brought; and secondly, there is the defensive medicine fear, that medical practices must be adopted in case actions for negligence are brought. One can see immediately one cause for the pervasiveness of this fear of litigation harassment: the evidence, whatever it happens to be, supports the feeling of harassment. If civil actions are brought, then the floodgates have been opened; if they are not, it is due to the introduction of defensive practices. Part of the problem is undoubtedly the current lack of systematic research evidence on these matters. Instead, the fear is fuelled by an unlimited number of anecdotes, an observed rise in medical insurance premiums and damage awards and the ever-present spectre of the American example.

In the absence of systematic evidence and empirical justification, there is the greatest need for a balanced and detailed analysis of some of these perceptions. A good starting point for this is a fuller understanding of English and American litigation practice from which it will be seen that some of the assumptions underlying these fears lack foundation. Litigation - bringing legal proceedings - is not a costless activity; indeed, the reverse is true. It is rarely, if ever, a step embarked upon lightly or vexatiously. Numerous studies have demonstrated that victims of negligence are reluctant to pursue a remedy, that pressures against individual claimants weigh heavily against them and that there are numerous barriers to 'access to justice'. Victims have difficulty obtaining and, more importantly, affording legal services. The risks, costs and uncertainties of litigation are great, there is a heavy price for failure: lost cases are expensive (6). In the medical context particularly, victims may have difficulty recognising defective treatment and even greater difficulty finding and proving evidence of fault. In this regard, the question has to be asked: what is and what should be the responsibility of health care professionals in removing some of the barriers to access to justice? This includes the question, to what extent should information be disclosed to patients before, during and after treatment?
It becomes somewhat difficult therefore to reconcile the fact that complaints against the litigation process emanate from both the health care side and the user side. One response could be to argue that Britain is currently in only the first stage of an American-style malpractice explosion and that steps need to be taken to prevent the arrival of further stages. Yet this argument fails to address significant differences in the American system; it merely assumes that the two countries are comparable. To be taken seriously, the prophets of doom must explain why the malpractice crisis occurred in the United States. Is not the American experience a function of legal and health care systems so different from ours as to make comparisons and forecasts based upon it both superficial and misleading (8)?

Regarding the legal system, the presence of juries in American trials undoubtedly leads to much greater awards of damages than would be given by British judges sitting without juries. The vision of a victim of negligence rarely shocks or outrages judges used to seeing or hearing about their injuries. Most members of a jury, however, cannot fail to feel the greatest sympathy and their natural response will be to award colossal sums in damages, perhaps even in cases where the existence of negligence is in doubt if the alternative is that the victim goes uncompensated. A second major difference in the American legal system is the 'contingency fee' system, whereby lawyers representing victims of negligence take a share, usually around one-third, of any judgement award or settlement figure, or nothing, if their clients lose. Thus, to compensate a victim to the tune of $\$ 100,000$, the jury needs to award $\$ 150,000, \$ 50,000$ of which (one-third) will go to the lawyer. The contingency fee system may also encourage more victims to sue since they undertake little, if any, financial risks. This is only a problem if dubious cases are being brought, where, for example, negligence has not occurred, but the lawyer can play upon the emotions of jurors, or force insurance companies to settle out of court for fear of what jurors might do. Such a problem does not exist here; in fact, our system very often has the opposite effect. Victims who have fairly strong cases may settle $\mathcal{N}$ for less than full compensation because of fears that $N$ they will incur enormous costs, especially at trial. N Although the 'winner' in a civil action can recover most 0 of their legal costs from the 'loser', the probability of winning is rarely, if ever, 100 per cent. Very few claimants can ignore the risk of losing, not even legally aided claimants.

The methods of delivering legal services in Britain are under review, and concern has been expressed $\mathbb{\Phi}$ within the medical profession regarding the recent $\overrightarrow{\mathbb{D}}$ proposal to introduce a 'contingency' system here (9). ํㅏㅇ This, together with the relaxation of rules against advertising by solicitors, are seen as yet more signs of $\delta$ an American-style crisis. These fears are misconceived. The proposals under review do notô․

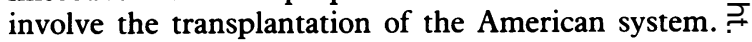


Such a transplant has been rejected by both branches of the legal profession and a recent Royal Commission (10) - indeed, to adopt a contingency scheme in litigation would currently be unlawful. Moreover, were the American version actually to be transplanted, then, in a medical sense, it would be rejected, because it would not fit in with the host legal system as it is structured at the moment. The proposals put forward by the Law Society do not entail the lawyer taking a share in the 'winnings'. Instead, winning parties would pay a share of their damage awards into a contingency fund. Lawyers would be paid reasonable fees from this fund whether they won or lost the case. The hope is that the undesirable features of the American system lawyers with a vested interest in the outcome and victims with borderline or small claims being unrepresented - would be avoided.

Regarding advertising by solicitors, what has the medical profession to fear? Does the medical profession wish victims of negligence to go uncompensated? It may be that advertisements by solicitors offering to help patients bring actions against doctors will result in an increase in litigation against doctors. But it does not follow automatically that this will have a detrimental effect on medical care in general. If victims of negligence, who require legal advice in order to obtain compensation, are able to get it as a result of advertising, then, if the standard of care imposed by the law is appropriate and if the costs of pursuing claims are not outrageous, the result will be an improvement in medical care. The fear that advertising will lead to a flood of unmeritorious claims has been discussed above. Such fears simply ignore the barriers to the bringing of all claims, including genuine ones.

Regarding the health care system in the United States, this too is significantly different from ours. It is much more expensive. It is a private sector service for the most part and the financial arrangements operating within the American system are very different. Thus, it would not be surprising if the need for the containment of costs in the provision of American medical care is the consequence of the nature of health insurance rather than the spread of malpractice suits. Defensive medicine may be more significant as an indicator of the weakness of cost constraints in the medical care system than of failures in the litigation system. In other words, prolixity, over-extensive treatment, tests and the like may have more to do with the financial arrangements of American medical care than the malpractice suit (2).

This is not to say that there is not a malpractice crisis. It is to say that litigation and the negligence action should not be taken out of the context of the financial and institutional arrangements surrounding the provision of medical services. Compensation costs more in the United States: juries, contingency fees and an expensive health care system see to that. It is therefore a totally inappropriate model in this respect; the American malpractice crisis need not be avoided, it should be ignored. Instead, what is urgently required is analysis of our own domestic arrangements and systematic research to tackle the many unanswered questions. For example, why has there been an increase in litigation, and, indeed, in a willingness to complain? There may have been some institutional changes in the provision of complaints procedures and in the legal system (there may, for example, have been some slight widening of liability for 'negligence'). While these do not appear to have been substantial, they still require investigation and analysis. But so too do other explanations. Has there been an increase in negligence; are standards falling? Is more 'malpractice' being discovered; is public perception one of falling standards? Conversely, are public expectations unrealistically high and therefore often unfulfilled? Are users of the health service, like all citizens, becoming increasingly aware of their rights, of the duties owed to them by health care professionals, and of the legitimacy of vindicating their grievances? Is the ideal of professionalism in decline; is more accountability being demanded? Have the attitudes of the medical profession changed? Increased use of deputised services and large group practices may contribute to a breakdown in the doctor-patient relationship. The list of questions is infinitely and easily extendible. Their importance is such however that research must be commissioned to find some of the answers.

In the meantime, no doubt, fears about defensive medicine will continue to be expressed. However, the validity of these, in the litigation context, depends upon the existence either of a rash of unjustified suits or of excessive awards. There is little or no evidence of either. Perhaps what is needed is a clearer conception of defensive medicine. Do we call defensive medicine those practices which improve the quality of care? Do we call defensive practices those practices which are cost-justified, in that for some expense, greater potential losses of victims are avoided? Many so-called defensive practices are precisely the quality improvements that should be encouraged. On the other hand, quality improvements undertaken in order to avoid liability may be unjustified, and, despite the rather generous standard of care imposed by law, no doubt some defensive practices will take place, perhaps encouraged by the defence societies. But, in terms of the objectives of complaints procedures, the risk and cost of defensive medicine must be balanced against the general benefits of liability in deterring negligence. In this sense, litigation will only suffer a disadvantage if the balance is askew.

If the balance is not askew, then, prima facie, we should all welcome civil liability as a method of complaint and redress. However, as mentioned above, litigation suffers from other potential disadvantages as a complaints mechanism. Its major deficiency is its cost. Cases take many years to be determined, and for every $£ 100$ recovered, anywhere from $£ 50$ to $£ 70$ goes on legal costs. In the medical context, it is conceivable that one arm of the State via legal aid finances 
proceedings against another, a health authority, purely, cynics might say, for the benefit of the lawyers: It is the simple fact that litigation is such an expensive and uncertain process that it may be an unsuitable procedure for complaints. In addition, it is a procedure designed exclusively to compensate the victims of negligence, and not to compensate the victims, for example, of 'medical' accidents where the damage or injury was nobody's fault. The needs of a child born handicapped are the same whether the handicap was the result of negligence or nature. However, assessment of the suitability or otherwise of litigation must be made on the basis of its effects on all parties, of its effectiveness in achieving the goals of compensation and deterrence and of the virtues or otherwise of alternative procedures for complaint and redress.

\section{Alternative procedures}

Criticism of the legal system is possibly the only common ground concerning complaints procedures shared by the health care profession and representatives of patients, users and victims. Accordingly, in this section, I wish to review, very briefly, procedures which can be employed as an alternative to litigation. It is possible that current (and future) attempts to reform the civil justice system may help to restore its credibility, but it is also likely that alternatives to it will continue to be proposed.

\section{NO-FAULT SCHEMES}

No-fault schemes are advocated by both sides of the complaints argument. This is enough to make many lawyers very suspicious of the concept of no-fault. In principle, it involves the substitution of the tort liability scheme administered by the courts with some alternative scheme created by the legislature whereby accident victims receive compensation regardless of fault. A number of no-fault schemes have been introduced in other countries, New Zealand and Sweden being the most notable, and a no-fault scheme has recently been proposed by the British Medical Association (BMA) (11). The details of such schemes are beyond the scope of this paper (12), but if one is to be introduced, a variety of important problems concerned with its detail would have to be resolved. Which 'incidents' qualify for compensation? Who should be covered by such a scheme? If fault is to remain at issue, how will costs be kept down? If civil liability is to remain alongside a no-fault scheme, what is to be the relationship beween them? How should they be funded?

A major attraction of a no-fault scheme as compared with the tort system is that it separates the criteria for entitlement to compensation (that is, the question of the needs of victims: who gets the benefits and how much?) from the criteria under which the system is funded (that is, who pays and how much?). The tort system does, or attempts to do, both. However, both criteria still have to be addressed by advocates of no- fault schemes. It is no use proclaiming the merits of a scheme which answers the question of compensation without, at the same time, answering the question of how the quality of service is to be controlled (the deterrence goal). It is for this reason that the recent BMA proposal for a no-fault scheme has been criticised, by the charity Action for the Victims of Medical Accidents, as 'half-baked' (11). If a no-fault scheme creates no incentives for the medical profession to take care and if civil liability is abolished, from where are incentives and controls to come? Under the New Zealand no-fault scheme, information about 'accidents' is referred automatically to the licensing authority. How willing is the British medical profession to share information and records concerning accidents?

\section{PROFESSIONAL ETHICS}

Self-regulation is the hallmark of a profession, and ethical codes (as well as the articulation and enforcement of minimum standards) may be a substitute for costly legal methods of maintaining quality. Such codes may be based upon regulation within the profession backed up by disciplinary proceedings and sanctions.

It is not unusual for professional codes to limit their jurisdiction to cases of gross professional negligence with the result that 'ordinary' negligence is not defined as serious professional misconduct. This has been the case with most professional bodies in the United Kingdom, including the General Medical Council. Whatever the merits in such restrictions of jurisdiction (one common argument is that an expanded jurisdiction places professionals in a position of 'double jeopardy' with potential action being brought against them in the courts as well as within the profession), they clearly limit both the effectiveness and the credibility of self-regulation. It is in response to such concerns that the Law Society has reformed its professional complaints procedure and is considering further reform. However, a further problem of professional codes of ethics is that they may be, and often are, a euphemism for a quiet life which is not in the best interests of patients or the health care system. There are also the problems associated with the methods by which ethical standards are established, and how they are monitored and used.

\section{CONCILIATION/MEDIATION AND ARBITRATION}

The quest for 'alternative methods of dispute resolution' outside the courts has, in some respects, turned into a bandwagon, especially in the United States. In the medical context, both malpractice arbitration and mediation panels have been proposed as a cheaper (and speedier) alternative to the courts. The special issues raised by these alternatives cannot be explored here, but in many respects, the general issues are no different from those raised earlier in this paper. 


\section{INTERNAL COMPLAINTS PROCEDURES/TRAINING}

The introduction of complaints procedures under the Hospital Complaints Procedure Act 1985 and the appointment of complaints officers within the health service, the greater use of consent forms and the expansion of training are all 'internal' responses to the problem of complaints. In terms of the objectives of complaints procedures outlined above, it is important that internal complaints mechanisms do not degenerate into cosy arrangements imposed upon users of the health service. Moreover, if complaints officers are to be designated, they should co-ordinate their experience to ensure that they can not only respond to complaints but actively seek to prevent adverse incidents. Furthermore, while training in communication skills may help to improve the "bedside manner', the use of consent forms and the disclosure of information to patients should not be viewed (as perhaps the defence unions suggest) as a certain defence to legal action. The whole question of informed consent and accepted responsibility (which, it is claimed, also means that the patient is responsible for outcomes) is a thorny one which requires greater analysis of the nature of choice and consent in a medical setting.

\section{Conclusion}

It is likely that the already wide range of mechanisms by which complaints may be processed will be expanded in years to come. In 1987, for example, directions and guidance with statutory force concerning a hospital patients complaints procedure were made by the Secretary of State for Health and Social Security. Despite this variety of mechanisms however, it is the theme of this paper that the effectiveness of each of them should be evaluated by reference to the goals of deterrence and compensation as defined above. Utilising what is in essence a single yardstick to measure a range of procedures facilitates effective comparison and assessment. Moreover, and most importantly, this approach facilitates an analysis which takes into account the social costs of providing medical services.

If there is a second theme running through this review of complaints procedures it is the demand that analysis and debate be based upon reliable data and not on anecdote or prejudice. All sides of the debate over complaints procedures would benefit by the availability of accurate information; perhaps all sides should join together to foster and co-ordinate new research. For without such research, the debate will continue to get nowhere, with both sides adopting irreconcilable positions. In this adversarial climate (an attitude for which lawyers are often criticised), most complaints procedures are probably doomed to failure.

Dr Christopher $\mathcal{f}$ Whelan LL B PhD is Lecturer in Law in the University of Warwick School of Law.

\section{References}

(1) Schwitzgebel R L and R K. Law and psychological practice. New York: John Wiley, 1980.

(2) Quam L, Dingwall R, Fenn P. Medical malpractice in perspective I: the American experience. British medical journal 1988; 294: 1529; Quam L, Fenn P, Dingwall R. Medical malpractice in perspective II: the implications for Britain. British medical journal 1988; 294: 1597.

(3) Rolph E, Lindsey P. Medicare prospective payment system. Santa Monica, Ca: Rand, 1986.

(4) American Medical Association Center for Health Policy Research. Preliminary estimates of the cost of medical professional liability. Chicago: AMA, 1985.

(5) The future basis of professional indemnity insurance, self-insurance. Law Society gazette 1986; Oct 16: 30473053.

(6) Empirical support for this proposition can be found in Harris D R, Maclean M, Genn H, Lloyd-Bostock S, Fenn P, Corfield P, Brittan Y. Compensation and support for illness and injury. Oxford: Clarendon, 1984: 318.

(7) Royal Commission on Civil Liability and Compensation for Personal Injury. Lord Pearson, chairman. Cmnd $7504,1978$.

(8) For a full review of the literature on both the British and American experience, see Quam L, Dingwall R, Fenn P. Professional liability and medical practice: a critical bibliography. Oxford: Oxford University, Centre for Socio-Legal Studies, (forthcoming). A brief analysis is available in Quam et al: See reference (2).

(9) Law Society. Improving access to civil justice: the report of the Law Society's working party on the funding of litigation. 1987; Jul. An earlier proposal was Justice. CLAF: proposals for a Contingency Legal Aid Fund 1978.

(10) Royal Commission on Legal Services. Lord Benson, chairman. Cmnd 7648, 1979.

(11) The Times 1987 March 11:3.

(12) The no-fault schemes which operate in other countries are discussed in the Pearson Report: See reference (7), and also Brahams $M$. The Swedish 'no fault' compensation system for medical injuries. New law journal 1988; Jan 8: 14, Jan 15:31. 